\title{
Review of the endometrial safety during intravaginal treatment with estriol
}

\author{
G.P. Vooijs* ${ }^{a, 1}$, T.B.P. Geurts ${ }^{b}$ \\ ${ }^{a}$ Faculty of Medical Sciences, University of Nijmegan, Geert Grooteplein 9.6525 EC Nijmegen, The Netherlands \\ ${ }^{b}$ Medical Services Department, N.V. Organon, Oss, The Netherlands
}

Received 25 January 1995; revision received 4 April 1995; accepted 10 May 1995

\begin{abstract}
To gain more insight into whether intravaginal treatment of local urogenital complaints with the mild-acting oestrogen estriol is capable of inducing proliferaton of the endometrium, the results of the clinical studies that have been published over the years have been pooled. Of a total of 19 studies that initially had been selected, four were excluded from the analysis because no baseline biopsies were available, two because endometriae had been evaluated using methods other than with histology, and one study because a sustained-release preparation was used. Pooling of 12 studies (214 subjects) revealed a reasonable amount of long-term data on intravaginal estriol treatment with 61 evaluable biopsies after 6 months and 58 after 12 months. In addition, 13 biopsies were available after 2 years. It appeared that intravaginal estriol treatment using the recommended dosages did not result in endometrial proliferation. All 337 post-baseline biopsies that have been reported in the literature were classified as atrophic. It can be concluded that single daily treatment with intravaginal estriol in the recommended doses in postmenopausal women is safe and without an increased risk of endometrial proliferation or hyperplasia. Consequently, there is no need to add sequential progestogens with these preparations and no withdrawal bleedings will be induced.
\end{abstract}

Keywords: Intravaginal estriol; Endometrial proliferation; Progestogens

\section{Introduction}

During the reproductive years, the three endogenous estrogens of importance are $17 \beta$-estradiol, estrone and estriol. About 5 years before the menopause, the endogenous production of $17 \beta$-estradiol starts to decrease, and after the menopause this production ceases almost completely. Consequently, estrone and (to a lesser extent) estriol become the main circulating endogenous estrogens. This decrease in endogenous estrogen production may result in a number of climacteric symptoms, including irregular bleeding, hot flushes, atrophyrelated urogenital symptoms, and an increased risk of both osteoporosis and cardiovascular disease.

Epidemiological data have indicated that about 50\% of otherwise healthy women over 60 years have symp-

\footnotetext{
* Corresponding author, Tel.: +31 80 615345; Fax: +31 80540704 . 'Professor Voijs was previously Head of the Department of Pathology of the Sint Radboud University Hospital, Nijmegen, The Netherlands.
}

toms related to urogenital atrophy [1]. The clinical symptoms are vaginal dryness, dyspareunia, itching, miction complaints, recurrent vaginal infections and lower urinary tract infections. Since estriol induces normalization of the vaginal, cervical and urethral epithelium [2,3] and thus helps to restore the normal microflora and the physiological $\mathrm{pH}$ in the vagina [4-6] both intravaginal and systemic treatment with estriol increases the resistance of the vaginal epithelial cells to infection and inflammation [4-6] and decreases the incidence of urogenital complaints $[2,5,6]$. Consequently, the use of exogenous estriol (Ovestin ${ }^{\circledR}$, Colpogyn ${ }^{\circledast}$, Ortho-Gynest ${ }^{\oplus}$ ) has now widely been accepted as the preferred medication in the treatment of atrophy of the lower urogenital tract.

Unopposed estrogen replacement therapy with $17 \beta$ estradiol and conjugated estrogens has been associated with an increased risk of endometrial hyperplasia which may lead to endometrial carcinoma [7,8]. In order to prevent this, progestogens need to be added. Progesto- 
gen administration induces a secretory transformation of the endometrium followed by a withdrawal bleeding [9]. However, sequential addition of progestogens has negative effects since it induces thus a recurrence of cyclical withdrawal bleedings which is not acceptable to most postmenopausal women and which has been identified as a major cause of non-compliance $[10,11]$. Furthermore, other progestogen regimens such as continuous addition of progestogens may lead to unexpected irregular bleeding [12], which may also contribute to non-compliance. Finally, some of the positive effects of estrogen use, such as an improvement of the plasma lipid profile, may be diminished or even reversed by progestogen addition $[13,14]$.

In this context, it is relevant to investigate whether also treatment with a mild acting estrogen such as estriol can lead to endometrial hyperplasia and thus whether progestogen addition is needed with estriol treatment. Whereas with respect to $17 \beta$-estradiol and conjugated estrogens there is an abundance of clinical and epidemiological evidence that there is indeed a relationship with endometrial hyperplasia and carcinoma, with estriol treatment such a relationship has not been found, although the amount of epidemiological data is limited. As a result of its pharmacological profile, the risk of endometrial proliferation with estriol seems to be absent, since receptor binding studies have indicated that estriol has only low relative binding affinity to endometrial estrogen receptors (about $10 \%$ of $17 \beta$-estradiol), whereas it has a relatively strong binding affinity to vaginal estrogen receptors (equal to $17 \beta$-estradiol). This means that after a single dose of estriol, the binding to the endometrial estrogen receptor is too short to induce true proliferation, while its binding to the vaginal estrogen receptor is sufficient to exert a full vaginotropic effect [15]. This lack of endometrial proliferation has been supported by data from two epidemiological studies on estriol showing that there is no increased risk of endometrial carcinoma $[16,17]$. It can therefore be argued that with estriol treatment, when used in the recommended single daily dosages, the risk of endometrial hyperplasia is probably absent.

The objective of this review is to gain more insight in the effects of intravaginally administered estriol on the endometrium by pooling the results of the clinical studies that have been published over the years.

\section{Methods}

Literature from the period from the end of the $1950 \mathrm{~s}$ (when estriol became available to the market) up to June 1994 was identified with help of detailed literature searches in commercial on-line databases (MedLine, Embase, Biosis, Current Contents) as well as with the help of in-house electronic literature databases and literature collections.
By checking the contents of the papers it was also attempted to exclude duplicate publications as far as possible, but since such papers often cannot be identified it may be posible that occasionally (parts of) duplicate data sets have been included. Studies evaluating the effects of oral preparations or intravaginal sustainedrelease preparations were also excluded from the analysis, since their pharmacokinetic and pharmacodynamic characteristics are thought to differ considerably from the intravaginal formulations. Finally, studies in which the endometrial biopsies were not evaluated by use of light microscopy were excluded from the analysis, since the typical definitions of atrophic, proliferative, secretory and hyperplastic endometria are based on the light-microscopical picture.

Requirements for inclusion were that from a particular study both baseline and follow-up biopsies should be available, since it is not uncommon for peri- and postmenopausal women to present with endometrium proliferation irrespective of estrogen use $[9,18]$. Absence of baseline biopsies makes it therefore impossible to determine causality with estriol use. Another requirement for a paper to be included was that the subjects should be postmenopausal. It was further decided to restrict this review to intravaginal administration, i.e. cream or suppositories, only in the recommended dosages $(0.5 \mathrm{mg}$ - one application, resp. one suppository - per day for the first 2-3 weeks, followed by a gradual reduction to $0.5 \mathrm{mg}$ twice a week).

All studies that complied with the in- and exclusion criteria were evaluated with respect to the effects of estriol treatment on the endometrium. The evaluated and classified endometrial biopsies in the papers were tabulated and the proportion of biopsies that showed endometrial proliferation was subsequently analyzed. A complicating factor in analyzing endometrial histological data was that usually no exact definitions were presented for atrophy, proliferation, secretion and hyperplasia. However, in many light microscopy studies criteria similar to those below were used $[18,19]$ :

- atrophic endometrium: this broad category includes the patterns of marked atrophy, inactive cystic endometrial atrophy of perimenopausal type, posthyperplastic atrophy and progestogen-suppressed endometrium. Some epithelial snouts and vacuoles may be present;

- proliferative endometrium: the endometrium shows discernible evidence of stimulation - the tissue is composed of single round or oval glands surrounded by a densely packed stroma. As a sign of active growth in both structures, numerous mitoses indicating cell division can be easily found;

- hyperplastic endometrium: a spectrum of glandular patterns, crowding (glands at the expense of stroma) and cytological abnormalities characterize the diagnostic 
subcategories of cystic, adenomatous, and atypical hyperplasia. During persistent oestrogenic stimulation, glandular cystic hyperplasia may progress to adenomatous hyperplasia. Proliferating glandular epithelial cells cause a relative overgrowth of stroma cells and hyperestrogenism becomes manifest by the appearance of foam cells. Atypical hyperplasia is a more advanced stage and the glandular abnormalities are more closely related to those of adenocarcinoma. The lesion is characterised by large glands which lie closely together but are still separated by definite stroma strands. The glandular epithelial cells are frequently enlarged and pseudostratified. The glandular lining epithelium may show papillary folding. The cytoplasm is amphophilic or basophilic and the nuclei are enlarged and often differ in size. They may have a basal or intermediate position and show stratification and sometimes a slightly altered polarity. The nuclear chromatin is coarsely granular and unevenly distributed. Mitoses are common and the increased polymorphism of glandular cells is usually not evenly distributed within the glandular epithelium; - secretory endometrium: glands may show subnuclear glycogen vacuoles with more advanced secretory change and glands are tortuous with luminal secretion. Stroma is hypertropic with peri-arteriolar cuffing. Mitoses are rare or absent.

\section{Results}

A total of 19 possibly relevant studies were identified. Four studies were excluded from the analysis because from these, no baseline biopsies were available [20-23]. Three other papers were excluded because no biopsies had been taken and endometrium proliferation was evaluated otherwise, i.e. by induction of withdrawal bleeding with progestogens $[24,25]$ or with the help of scanning electron microscopy (SEM) [26]. Finally, a study with a sustained-release estriol preparation was also excluded [27]. In three of the excluded papers signs of endometrial stimulation or other estrogenic effects have been reported $[22,25,26]$. In the electron microscopy study ciliogenesis with longer microvilli was observed in the estriol-treated group as compared to an untreated control group [26]. Although these effects can be explained as estrogenic in nature [28,29], it is unknown whether such estriol-induced effects as observed with SEM are synonymous with the light-microscopical phenomenon or with endometrial proliferation. Another limitation of this study was that no baseline assessments had been performed, leaving the possibility open that the effects were already present at baseline. In another excluded study where signs of endometrial stimulation were reported [22], no baseline biopsies had been taken and only indirect histological indices ('no influence', 'moderate influence', or 'full influence') were presented, making it impossible to determine a causal relationship
Table 1

Number of evaluable subjects per study at baseline and per treatment period (for all post-baseline biopsies an atrophic endometrium biopsy was present)

\begin{tabular}{|c|c|c|c|c|c|c|c|c|c|c|}
\hline Reference & $\mathrm{BL}$ & $2 \mathrm{~W}$ & $3 W$ & $1 \mathrm{M}$ & $2 \mathrm{M}$ & $3 \mathrm{M}$ & $4 \mathrm{M}$ & $6 \mathrm{M}$ & IY & $2 \mathrm{Y}$ \\
\hline Babuna [30] & 16 & 4 & - & 6 & 5 & 3 & 12 & - & - & - \\
\hline Boselli [31] & 63 & - & - & - & - & 63 & - & 38 & 15 & 3 \\
\hline Boselli [32] & 20 & - & - & - & - & - & - & - & 20 & 10 \\
\hline Genazzani [33] & 12 & 12 & 12 & - & - & - & - & - & - & - \\
\hline Gerbaldo [34] & 23 & - & 一 & - & - & - & - & 23 & 23 & - \\
\hline Kicovic [35] & 16 & - & 16 & - & - & - & 8 & - & - & - \\
\hline Lauritzen [36] & 8 & - & - & 8 & - & - & - & 一 & - & - \\
\hline Luisi [37] & 2 & 2 & - & - & - & - & - & - & - & - \\
\hline Mattsson [38] & 6 & 6 & - & - & - & - & - & - & - & - \\
\hline Milojevic [39] & 7 & - & - & 7 & - & - & - & - & - & - \\
\hline Trevoux [40] & 15 & - & 15 & - & - & - & - & - & - & - \\
\hline van der Velden [41] & 26 & - & 26 & 一 & 一 & - & - & 一 & - & 一 \\
\hline Total & 214 & 24 & 69 & 21 & 5 & 66 & 20 & 61 & 58 & 13 \\
\hline
\end{tabular}

with estriol. In the third study, in 7 out of 48 postmenopausal women there were signs of weak proliferation after 8-10 years of estriol treatment [25]. However, since no baseline biopsies were performed, the relationship with estriol is questionable.

Twelve studies were included in the analysis [30-41]. The total numbers of evaluable subjects per study at baseline (BL) and after 2 weeks ( $2 \mathrm{~W}), 3$ weeks ( $3 \mathrm{~W}), 1$ month (1M), 2 months (2M), 3 months (3M), 4 months $(4 \mathrm{M}), 6$ months $(6 \mathrm{M}), 1$ year (1YR) and 2 years (2YR) are presented in Table 1 .

Table 1 indicates that pooling of the published data revealed a reasonable amount of long-term data on intravaginal estriol treatment with 61 resp. 58 evaluable biopsies after 6 and 12 months. In addition, 13 biopsies were available after 2 years of treatment.

From the results of the 12 studies mentioned in the table, encompassing a total of 214 subjects, it appears that intravaginal estriol treatment using the recommended dosages by postmenopausal women did not result in endometrial proliferation, not even after longterm (2 years) treatment. All 337 post-baseline biopsies were classified as atrophic by the authors of these papers. In addition, in the study by Lauritzen [36] even intravaginal treatment in a subgroup of subjects with 3 $\mathrm{mg} /$ day estriol for 1 week (not included in the tables), which is six times the recommended dose, did not induce endometrial proliferation.

\section{Discussion}

Estriol binds to the uterine estrogen receptor, forming a complex which ultimately accumulates in the cellular nucleus and attaches to specific binding sites. Of all the natural estrogens, estriol has the shortest receptor oc- 
cupancy. The reasons for this are not clear but there are several possible explanations: a rapid dissociation from the estrogen receptor, a rapid plasma clearance and/or a rapid dissociation of complexes from nuclear binding sites. The critical binding period for stimulation of DNA synthesis and thus for endometrium proliferation lies between 9 and $12 \mathrm{~h}$ after first interaction, and when around this time point enough estrogen is bound to the receptor (e.g. after multiple daily doses or after high oral doses), stimulation of DNA synthesis will occur and a uterotropic response may be seen [42-45]. As a result of the short duration of receptor binding of estriol following single daily doses, DNA synthesis is not stimulated and proliferation of the endometrium can therefore not occur. On the other hand, estriol exerts a full vaginotropic response. This differential effect on vaginal as compared to endometrial tissue may partly be explained by the presence of an estrogen-binding protein in the vagina which is not present in the endometrium. It has been demonstrated that estriol has a relatively high binding affinity to this vaginal protein [15].

Another consequence of the short duration of action of estriol at the receptor level is that there are hardly any systemic effects: studies indicate absence of effects on blood pressure [38], body weight [38], liver function [35], hemostasis [35,36], lipid metabolism [35,36] and bone metabolism [46]. With respect to effects of estriol on breast cancer risk, the available data give no reason for concern [47].

The decision to exclude studies from which no baseline biopsies were available is justified by the fact that at baseline endometrial proliferation may have been present: in a study in asymptomatic, predominantly white peri- and postmenopausal women it was reported that about $22 \%$ of endometrial biopsies showed proof of either proliferation or hyperplasia [18].

The results from studies with single daily intravaginal estriol treatment in postmenopausal women in the recommended dosages clearly and consistently demonstrate that endometrial proliferation does not occur. In addition, the findings in this review concur with the above mentioned mechanism of action studies in that with single daily intravaginal estriol treatment the binding to the endometrial estrogen receptor is too short to induce a proliferative effect. The findings are also in accordance with recent literature on the subject [5,48-50].

The limitations of the current findings are also clear: these results are only applicable to intravaginal estriol formulations and dosages mentioned in the 'Methods' section of this paper. No firm conclusions can be drawn with respect to oral preparations, intravaginal preparations using dosages higher than those recommended in this paper, multiple daily dosages or sustained-release preparations, because of differences in pharmacokinetic and/or pharmacodynamic characteristics. Nevertheless, available epidemiological studies indicate that with estriol treatment in general there is no increased risk of endometrial cancer [16,17]. Another limitation of the current findings is that in the various studies, endometrial biopsies have been evaluated by different investigators who also may have used different standards and different subjects. However, since the results from all included studies show a non-response of the endometrium, they are probably generally applicable.

The main clinical implication of the lack of endometrial response is that with intravaginal estriol treatment, unlike treatment with longer-acting estrogens such as $17 \beta$-estradiol or conjugated estrogens, no sequential progestogen addition is needed to prevent endometrial hyperplasia. Consequently, cyclical withdrawal bleeding will not be induced which has a positive effect on user compliance and a lack of potential progestogen-induced negative effects.

It can be concluded that single daily treatment with intravaginal estriol in the recommended doses in postmenopausal women is safe and without an increased risk of endometrial proliferation or hyperplasia. Consequently, there is no need to add sequential progestogens when using these preparations, not even for long-term treatment.

\section{Acknowledgments}

We thank Ms. CA Meihuizen, MD of N.V. Organon, Oss for her contribution to the analysis and interpretation of the data.

\section{References}

[1] losif CS, Bekassy Z. Prevalence of genito-urinary symptoms in the late menopause. Acta Obstet Gynecol Scand 1984; 63: 257-60.

[2] Haspels AA, Luisi M, Kicovic PM. Endocrinological and clinical investigations in postmenopausal women following administration of vaginal cream containing oestriol. Maturitas $1981 ; 3$ : $321-7$.

[3] Linden MCGJ van der, Gerretsen G, Brandhorst MS, Ooms ECM, Kremer CME, Doesburg WH. The effect of estriol on the cytology of urethra and vagina in postmenopausal women with genito-urinary symptoms. Eur J Obstet Gynecol Reprod Biol 1993; 51: 29-33.

[4] Brandberg A, Mellström D, Samsioe G. Low dose estriol treatment in elderly women with urogenital infections. Acta Obstet Gynecol Scand 1987; (Suppl. 140): 33-8.

[5] Raz R, Stamm WE. A controlled trial of intravaginal estriol in postmenopausal women with recurrent urinary tract infections. $N$ Engl J Med 1993; 329; 753 6.

[6] Kirkengen AL, Andersen P, Gjersфe E, Riis Johannesen G, Johnsen N, Bodd E. Oestriol in the prophylactic treatment of recurrent urinary tract infections in postmenopausal women. Scand J Prim Health Care 1992; 10: 139-42.

[7] Ziel HK, Finkle WD. Increased risk of endometrial carcinoma among users of conjugated estrogens. N Engl J Med 1975; 293: 1167-70.

[8] Smith DC, Prentice R, Thompson DJ, Hermann WL. Associa- 
tion of exogenous oestrogen and endometrial cancer. $\mathrm{N}$ Engl $\mathrm{J}$ Med 1975; 293: 1164-7.

[9] Gambrell RD. Do progestogens protect against endometrial cancer in estrogen users? In: Sitruk-Ware R, Utian WH, eds. The menopause and hormonal replacement therapy — facts and controversies. New York: Marcel Dekker, Inc., 1991: 119-41.

[10] Coope J, Marsh J. Can we improve compliance with long-term HRT? Maturitas 1992; 15: 151-8.

[11] Barentsen R, Groeneveld FPMJ, Bareman FP, Hoes AW, Dokter HJ, Drogendijk AC. Women's opinion on withdrawal bleeding with hormone replacement therapy. Eur J Obstet Gynecol Reprod Biol 1993; 51: 203-7.

[12] Archer DF, Pickar JH, Bottiglioni F, for the Menopause Study Group. Bleeding patterns in postmenopausal women taking continuous combined or sequential regimens of conjugated estrogens with medroxyprogesterone acetate. Obstet Gynecol 1994; 83: 686-92.

[13] Miller VT, Muesing RA, LaRosa JC, Stoy DB, Fowler SE, Stillman RJ. Quantitative and qualitative changes in lipids, lipoproteins, apolipoprotein A-1, and sex hormone-binding globulin due to two doses of conjugated equine estrogen with and without a progestin. Obstet Gynecol 1994; 83: 173-9.

[14] Rijpkema AHM, Sanden AA van der, Ruijs AHC. Effects of postmenopausal oestrogen-progestogen replacement therapy on serum lipids and lipoproteins: a review. Maturitas 1990; 12: 259-85.

[15] Bergink EW, Kloosterboer HK, Vies J van der. Oestrogen binding proteins in the female genital tract. J Steroid Biochem 1984; 20: $1057-60$.

[16] Salmi T. Risk factors in endometrial carcinoma with special reference to the use of estrogens. Acta Obstet Gynecol Scand 1979; (Suppl. 86): 1-119.

[17] Persson I, Adami HO, Bergkvist $L$ et al. Risk of endometrial cancer after treatment with oestrogens alone or in conjunction with progestogens: results of a preospective study. $\mathrm{Br}$ Med $\mathrm{J}$ 1989; 298: 147-51.

[18] Archer DF, McIntyre-Seltman K, Wilborn WW et al. Endometrial morphology in asymptomatic postmenopausal women. Am J Obstet Gynecol 1991; 165: 317-22.

[19] Vooijs GP. The morphology of endometrial proliferative reactions. In: Lauritzen C, Keep PA van, eds. Estrogen therapy the benefits and risks. Basel: S. Karger, 1978: 76-88.

[20] Fink RS, Collins WP, Papadaki L, O'Reilly B, Ginsburg J. Vaginal oestriol: effective menopausal therapy not associated with endometrial hyperplasia. J Gynaecol Endocrinol 1985; 1: $1-11$.

[21] Galli PA, Cerri R, Volpe A, Genazzani AR. Preliminary results on the use of intravaginal estriol cream in cases of minor postmenopausal urogenital disorders. Abstract presented at the annual meeting of the International Continence Society, London, September 1985. Proceedings of the 15th Annual Meeting of the International Continence Society, 1985: 365-6.

[22] Haaften M van, Donker GH, Sie-Go DMDS, Haspels AA, Thijssen JHH. Biochemical and histological effects of vaginal oestriol (E3) and oestradiol (E2) applications on endometrium, myometrium and vagina of postmenopausal women. In: Haaften $M$ van. Oestriol in postmenopause [dissertation]. Utrecht: Rijksuniversiteit, 1988: 41-59

[23] Tolino A, Ronsini S, Granata P, Gallo FP, Riccio S, Montemagno $U$. Traitement topique avec estriole de la vaginite atrophique post-ménopause. Rev Fr Gynecol Obstet 1990; 85: $692-7$.

[24] Heimer GM, Englund DE. Effects of vaginally-administered oestriol on postmenopausal urogenital disorders: a cytohormonal study. Maturitas 1992; 14: 171-9.

[25] Iosif CS. Effects of protracted administration of estriol on the lower genito urinary tract in postmenopausal women. Arch Gynecol Obstet 1992; 251: 115-20.

[26] Englund DE, Axelsson O, Nilsson BO. Endometrial effect of vaginal estriol treatment. Acta Obstet Gynecol Scand 1982; (Suppl. 106): 23-6.

[27] Foidart JN, Vervliet J, Buytaert P. Efficacy of sustained-release vaginal oestriol in alleviating urogenital and systemic climacteric complaints. Maturitas 1991; 13: 99-107.

[28] Nathan E, Knoth M, Nilsson BO. Scanning electron microscopy of the effect of short-time hormonal therapy on postmenopausal endometrium. Uppsala J Med Sci 1978; 83: 175-83.

[29] Nilsson O, Englund D, Weiner E, Victor A. Endometrial effects of levonorgestrel and estradiol: a scanning electrom microscopy study of the luminal epithelium. Contraception 1980;22: 71-83.

[30] Babuna C, Aksu MF, Erez R. Management of lower genital tract atrophy with a vaginal cream containing oestriol. In: Fioretti P, Martini L, Melis GB, Yen SSC, eds. The menopause: clinical, endocrinological and pathophysiological aspects. London: Academic Press, 1982: 557-62.

[31] Boselli F, Volpe A, Genazzani AR. Topical therapy: estriol vaginal cream in postmenopausal women. In: Genazzani AR, Volpe A, Facchinetti F, eds. Gynecological endocrinology. Carnforth: Parthenon Publishing, 1987: 687-94.

[32] Boselli F, Cicoli C, Volpe A, Genazzani AR. Endometrial morphology after long-term topical oestriol therapy in postmenopausal women. In: Abstracts of the 5th International Congress on the Menopause, Sorrento, April 1987. Carnforth: Parthenon Publishing, 1987: 75.

[33] Genazzani AR, Inaudi P, La Rosa R, De Leo V, Ricci-Danero MG, Danero S. Estriol and menopause - clinical and endocrinological results of vaginal administration. In: International Symposium on the Menopause: clinical, endocrinological and pathophysiological aspects, Viareggo, May 1980. Abstracts, 1980: 45.

[34] Gerbaldo D, Ferraiolo A, Croce S, Truini M, Capitanio GL. Endometrial morphology after 12 months of vaginal oestriol therapy in postmenopausal women. Maturitas 1991; 13:269-74.

[35] Kicovic PM, Cortes-Prieto J, Milojevic S, Haspels AA, Aljinovic A. The treatment of postmenopausal vaginal atrophy with Ovestin ${ }^{\otimes}$ vaginal cream or suppositories: clinical, endocrinological and safety aspects. Maturitas 1980; 2: 275-82.

[36] Lauritzen C. Erfahrungen mit einer Oestriol-Vaginalcreme. Ther Gegenw 1979; 118: 567-77.

[37] Luisi M, Franchi F, Kicovic PM. A group-comparative study of effects of Ovestin ${ }^{\star}$ cream versus Premarin cream in postmenopausal women with vaginal atrophy. Maturitas 1980; 2: $311-9$.

[38] Mattsson LA, Cullberg G. A clinical evaluation of treatment with estriol vaginal cream versus suppository in postmenopausal women. Acta Obstet Gynecol Scand 1983; 62: 397-401.

[39] Milojevic S, Kicovic PM. Pre- and post-operative treatment of atrophic vaginal mucosa with Ovestin ${ }^{\oplus}$ cream in postmenopausal women undergoing vaginal surgery. In: BakelMiddelweerd JM van, ed. News and views on oestriol. Leiden: De Medicus, 1985: 31-7.

[40] Trevoux R, Velden WHM van der, Popovic D. Ovestin ${ }^{\circ}$ vaginal cream and suppositories for the treatment of menopausal vaginal atrophy. Reproduccion 1982; 6: 101-6.

[41] Velden WHM van der, Trevoux R, Popovic D. Cream containing oestriol for the treatment of menopausal vaginal atrophy. In: Fioretti P, Martini L, Melis GB, Yen SSC, eds. The menopause: clinical, endocrinological and pathophysiological aspects. London: Academic Press, 1982: 535-8.

[42] Clark JH, Markaverich BM. The agonistic and antagonistic effects of short acting estrogens: a review. Pharmacol Ther 1983; 21: 429-53. 
[43] Harris J, Gorski J. Evidence for a discontinuous requirement for estrogen in stimulation of deoxyribonucleic acid synthesis in the immature rat uterus. Endocrinology 1978; 103: 240-5.

[44] Stack G, Gorski J. Relationship of estrogen receptors and protein synthesis to the mitogenic effect of estrogens. Endocrinology 1985; 117: 2024-32.

[45] Englund DE, Johansson EDB. Endometrial effect of oral estriol treatment in postmenopausal women. Acta Obstet Gynecol Scand 1980; 59: 449-51.

[46] Lindsay R, Hart DM, Maclean A, Garwood J, Clark AC, Kraszewski A. Bone loss during oestriol therapy in postmenopausal women. Maturitas 1979; 1: 279-85.
[47] Bergkvist L, Adami HO, Persson I, Hoover R, Schairer C. The risk of breast cancer after estrogen and estrogen-progestin replacement. N Engl J Med 1989; 321: 293-7.

[48] Krück F, Kaufmann $W$, Bünte $H$, Gladtke $E$, Tölle $R$, Wilmanns W, eds. Therapie Handbuch - Sexualität, Fertilität, Klimakterium. München: Urban and Schwarzenberg, 1992: L3-3/2.

[49] Kopera H, ed. Hormonelle Therapie für die Frau. Berlin: Springer Verlag, 1991: 70-1.

[50] Schneider HPG, Lauritzen C, Nieschlag E, eds. Grundlagen und Klinik der menschlichen Fortpflanzung. Berlin: Walter de Gruyter, 1988: 878-9. 